\title{
Oil-filled Lipid Nanoparticles Containing 2'-(2- bromohexadecanoyl)-docetaxel for the Treatment of Breast Cancer
}

\author{
Lan Feng, \\ Center for Nanotechnology in Drug Delivery, Division of Molecular Pharmaceutics, UNC \\ Eshelman School of Pharmacy, University of North Carolina at Chapel Hill, Chapel Hill, NC \\ 27599, USA
}

Soumya R. Benhabbour, and

Center for Nanotechnology in Drug Delivery, Division of Molecular Pharmaceutics, UNC Eshelman School of Pharmacy, University of North Carolina at Chapel Hill, Chapel Hill, NC 27599, USA

\section{Russell J. Mumper}

\section{Abstract}

A docetaxel (DX) lipid conjugate 2'-(2-bromohexadecanoyl)-docetaxel (2-Br-C16-DX) is synthesized to enhance the drug loading, entrapment and retention in liquid oil-filled lipid nanoparticles (NPs). The conjugate is successfully entrapped in the previously optimized NPs with an entrapment efficiency of $56.8 \%$. In-vitro release studies in $100 \%$ mouse plasma show an initial $45 \%$ burst release with no additional release within $8 \mathrm{hr}$. The conjugate is able to be hydrolyzed to release DX by esterases in-vitro. The conjugate is less potent than unmodified DX in DU-145 and 4T1 cells. However, NPs containing the conjugate show significantly higher cytotoxicity compared to its free form especially in $4 \mathrm{~T} 1$ cells. In-vivo, the $\mathrm{AUC}_{0-\infty}$ value of NP-formulated 2$\mathrm{Br}-\mathrm{C} 16-\mathrm{DX}$ is about 100-fold higher than DX formulated in Taxotere. Furthermore, 2-Br-C16-DX NPs improve DX AUC 4.3-fold compared to Taxotere. The high concentration and prolonged exposure of both 2-Br-C16-DX and DX from 2-Br-C16-DX NPs in circulation result in a 10-fold and 1.5-fold higher accumulation of 2-Br-C16-DX and DX, respectively, in tumors compared to Taxotere. In mice bearing syngeneic 4T1 tumors, 2-Br-C16-DX NPs show markedly greater anticancer efficacy as well as survival benefit over all controls. The results of these studies support that the oil-filled NPs containing hydrolyzable lipophilic DX prodrug 2-Br-C16-DX improve the therapeutic index of DX and are more efficacious in the treatment of breast cancer.

\section{Keywords}

ester prodrug; docetaxel; drug delivery; nanoparticle; oil-filled

\section{Introduction}

Docetaxel (DX) is a potent anticancer drug used to treat various cancers in clinic. ${ }^{[1-3]}$ Previously, liquid-oil filled NPs were developed to deliver DX. However, despite the

*John A. McNeill Distinguished Prof. R. J. Mumper, Corresponding Author, Center for Nanotechnology in Drug Delivery, Division of Molecular Pharmaceutics, UNC Eshelman School of Pharmacy, University of North Carolina at Chapel Hill, Chapel Hill, NC 27599, USA, UNC Lineberger Comprehensive Cancer Center, University of North Carolina at Chapel Hill, NC, USA, CB\# 7355, 100G Beard Hall, University of North Carolina at Chapel Hill, mumper@email.unc.edu. 
desirable formulation properties (e.g., monodisperse particle size, apparent drug entrapment efficiency, etc.), DX was found to be very quickly released in mouse plasma in-vitro. To overcome the poor retention of DX in the oil-filled NPs in simple aqueous phase and in biologically relevant medium, DX was modified by attaching fatty acid chains with different chain lengths to the 2'-position of DX via an ester bond. ${ }^{[4]}$ The three DX-lipid conjugates synthesized in the previous studies increased the drug solubility in oil phase by 10 -fold. Consequently, the DX-lipid conjugates were well retained in the NPs even in 100\% plasma. The retention of DX conjugates in the long-circulating NPs resulted in significantly reduced elimination and high and prolonged systemic drug exposure.

However, in-vitro cytotoxicity studies revealed that these DX conjugates were much less potent than the unmodified DX. ${ }^{[4]}$ Similar results have been reported by other groups. ${ }^{[5]}$ It has been long recognized that the 2'-OH is critical for the microtubule binding and cytotoxic effect of DX. ${ }^{[6]}$ Hence, the biological activity of these ester prodrugs mostly depends on the liberation of active DX. The compromised cytotoxicity suggests inefficient release of DX in cell culture. The in-vitro hydrolysis and in-vivo pharmacokinetics also revealed sub-optimal hydrolysis kinetics of these conjugates. ${ }^{[4]}$

Ali et al. synthesized a series of lipid paclitaxel (PX) prodrugs with or without a bromine atom at the 2-position on the fatty acid chain. ${ }^{[7]}$ In general, the prodrugs lacking bromine were 50- to 250-fold less active than their bromoacyl counterparts indicating that the electron-withdrawing group facilitated the cleavage of active PX. The bromoacylated PX showed higher anticancer efficacy against OVCAR-3 tumor in-vivo. ${ }^{[7,8]}$ Their findings suggest that this rationale and facile modification has the potential to favorably change the physicochemical and biological properties of the DX conjugates.

The objective of these present studies was to further tune the prodrug hydrolysis kinetics while retaining the high drug entrapment and retention in the oil-filled NPs. With optimized activation kinetics, the new prodrug containing NPs were expected to achieve sustained release of active drug, low systemic toxicity, and enhanced antitumor efficacy in-vivo.

\section{Results}

\subsection{Synthesis and characterization of 2-Br-C16-DX}

DX was modified to the more lipophilic prodrug, 2-Br-C16-DX, by a one-step esterification reaction with a 2-bromohexadecanoyl chain attached to the 2'-position of DX (Figure 1). The 2'-OH is the most reactive hydroxyl group among the multiple hydroxyl groups in DX molecule, followed by $7-\mathrm{OH}$ and $10-\mathrm{OH} .{ }^{[5]}$ The presence of bromine on the acyl chain made the carboxylic acid more reactive than its counterpart lack of bromine so that in addition to 2 '-substitution, byproducts with 7- and 10-substitution were also formed. Pure 2'monosubstituted DX conjugate was obtained after purification by preparative TLC and confirmed by TLC, NMR and mass spectrometry.

\subsection{2-Br-C16-DX digestion}

In fresh mouse plasma, $45 \%$ of 2-Br-C16-DX was hydrolyzed to DX in $48 \mathrm{hr}$ and $35 \%$ of 2$\mathrm{Br}-\mathrm{C} 16-\mathrm{DX}$ remained intact in $48 \mathrm{hr}$ (Figure 2). The mass balance did not reach $100 \%$ after $48 \mathrm{hr}$ incubation suggesting the presence of alternative degradation and/or metabolic pathways.

\subsection{Preparation and characterization of 2-Br-C16-DX BTM NPs}

The oil-filled NPs were able to entrap 2-Br-C16-DX with an entrapment efficiency of $56.8 \pm$ $2.8 \%$ as measured by SEC. The 2-Br-C16-DX NPs had a mean particle size of $210 \pm 2.15$ 
$\mathrm{nm}$ with a zeta potential of $-5.52 \pm 0.97 \mathrm{mV}$. The 2-Br-C16-DX NPs were physically and chemically stable at $4{ }^{\circ} \mathrm{C}$ upon long-term storage. The particle size slightly increased from $210 \mathrm{~nm}$ to $230 \mathrm{~nm}$ and 2-Br-C16-DX concentration in the NP suspension was unchanged for at least 5 months.

\subsection{In-vitro drug release in mouse plasma}

The release of 2-Br-C16-DX from NPs in 100\% mouse plasma was studied using the "exvivo" method developed in previous studies. ${ }^{[4]}$ Similar to our previous findings, an initial $45 \%$ burst release was observed upon spiking into the mouse plasma with no additional release within $8 \mathrm{hr}$ (Figure 3).

\subsection{In-vitro cytotoxicity}

The in-vitro cytotoxicity was evaluated in two cell lines; DU-145 human prostate cancer cells and 4T1 murine breast cancer cells. In DU-145 cells, free 2-Br-C16-DX was 16.4-fold less active than DX (Figure 4A). The cytotoxicity of 2-Br-C16-DX NPs increased 6.5-fold compared to free 2-Br-C16-DX, which was still 2.5-fold lower than DX.

In $4 \mathrm{~T} 1$ cells, free 2-Br-C16-DX was 2.8-fold less potent than DX (Figure 4B). When entrapped in NPs, the cytotoxicity increased 12.7-fold compared to free 2-Br-C16-DX. More impressively, the $\mathrm{IC}_{50}$ value of 2-Br-C16-DX NP was 4.5-fold lower than that of free DX. The blank NPs did not show significant cytotoxicity in either cell lines $\left(\mathrm{IC}_{50}\right.$ was $1842 \pm$ $287 \mathrm{nM}$ in DU-145 cells and $2955 \pm 435 \mathrm{nM}$ in $4 \mathrm{~T} 1$ cells with drug equivalent doses, respectively).

\subsection{In-vivo pharmacokinetics of 2-Br-C16-DX NPs}

The plasma concentration-time curves in mice receiving i.v. bolus injections of Taxotere or 2-Br-C16-DX NPs at a dose of $10 \mathrm{mg} \mathrm{DX} / \mathrm{kg}$ are shown in Figure 5A. Pharmacokinetic parameters obtained using a noncompartmental model of analysis are summarized in Table 1. The $\mathrm{AUC}_{0-\infty}$ value of NP-formulated 2-Br-C16-DX was about 100-fold higher than that of Taxotere. The DX concentration in plasma was below the lower limit of quantification after $8 \mathrm{hr}$, whereas 2-Br-C16-DX could be detected until $96 \mathrm{hr}$. The terminal half-life of NPformulated 2-Br-C16-DX was 8.7-fold higher compared to that of Taxotere. The plasma concentrations of DX hydrolyzed from 2-Br-C16-DX were determined and shown in Figure 5B. DX concentrations of Taxotere are also shown as a reference for comparison. The pharmacokinetic parameters of DX from 2-Br-C16-DX NP are also shown in Table 1. The DX from 2-Br-C16-DX NP was detectable until $24 \mathrm{hr}$ and below the lower limit of quantification after that. 2-Br-C16-DX NP improved DX AUC 4.3-fold compared to Taxotere. The terminal half-life of DX from 2-Br-C16-DX NP was comparable with that of Taxotere but its MRT was 6.4-fold higher than that of Taxotere.

The biodistribution of 2-Br-C16-DX and DX in main organs and tumors after i.v. administration of 2-Br-C16-DX NP and Taxotere is presented in Figure 6. The concentrations of DX from Taxotere in all organs rapidly decreased over time except for in tumors (Figure 6B). The lack of time-dependent elimination in the tumor likely reflects the abnormal tumor vasculature and dysfunctional lymphatic drainage. The overall concentrations of 2-Br-C16-DX were significantly higher than DX in all organs and tumors. A significant accumulation of 2-Br-C16-DX in liver and spleen was observed after the administration of 2-Br-C16-DX NP (Figure 6A). The 2-Br-C16-DX concentration in liver and spleen increased in the first several hours indicating the slow uptake of NPs by RES. The tumor accumulation of 2-Br-C16-DX and DX was shown in Figure 7. The $\mathrm{AUC}_{0-96}$ of 2-Br-C16-DX was 10-fold higher compared to Taxotere in 4T1 solid tumors (Table 2). The DX from 2-Br-C16-DX NPs in the tumor generally increased with time and the $\mathrm{AUC}_{0-96}$ 
was 1.5-fold higher than that of Taxotere. The $\mathrm{AUC}_{\text {plasma }}$ and $\mathrm{AUC}_{\text {tumor }}$ of Taxotere obtained in these studies are comparable with other reports in the literature. ${ }^{[9,10]}$

\subsection{In-vivo antitumor efficacy}

The antitumor efficacy of 2-Br-C16-DX NP was evaluated in a 4T1 breast cancer syngeneic mouse model. In the first study, mice were treated with a low dose of 2-Br-C16-DX NP and Taxotere with high dose frequency (10 mg DX or conjugate/kg, twice a week). The greatest tumor growth inhibition was observed with 2-Br-C16-DX NP treatment group (Figure 8). Taxotere and free 2-Br-C16-DX also showed some antitumor effect as compared to naïve group. A statistically significant difference of 2-Br-C16-DX NP with all other treatments was observed at day 13 and 15, with post-hoc least significant difference test.

In the second efficacy study, 2-Br-C16-DX NP was administered at predetermined MTD and dose frequency was adjusted to Q7d. Tumor volume increased with control, blank NPs, free 2-Br-C16-DX and Taxotere administration (Figure 9). The most significant tumor growth inhibition was observed with 2-Br-C16-DX NP treatment group. A statistically significant difference of 2-Br-C16-DX NP with all other treatments was observed starting from day 7 and continued to the end of the study, with post-hoc Tukey's test. Figure 10 shows the Kaplan-Meier survival curves of mice until day 23. The 50\% survival time of control, blank NPs, free 2-Br-C16-DX and Taxotere groups was between 14 days and 19 days. All mice in naive, blank NPs, free 2-Br-C16-DX and Taxotere groups died within 21 days. In 2-Br-C16-DX NP treatment group, 100\% survival through day 23 was observed.

\section{Discussion}

In the present studies, a lipophilic DX conjugate 2-Br-C16-DX was synthesized and characterized. The new conjugate was well entrapped and retained in the oil-filled NPs. The digestion kinetics of 2-Br-C16-DX was desirable. The retention of the conjugate in the longcirculating NPs, along with its very different digestion kinetics, resulted in a significantly improved pharmacokinetic profile, blood exposure of DX and tumor accumulation, which in turn led to superior antitumor efficacy.

Previously, three DX-lipid conjugates were synthesized to overcome the poor retention of DX in the oil-filled NPs. ${ }^{[4]}$ The $>10$-fold increase in the solubility of DX conjugates in Miglyol 808 compared to DX allowed for a significant increase in drug loading, entrapment and retention in plasma. However, as prodrugs, their digestion kinetics was not optimal. To further optimize the hydrolysis kinetics while retain the good drug entrapment and retention, the DX conjugate was modified by choosing a medium-chain fatty acid, and with a bromine at the 2-position of the lipid chain. The new DX conjugate 2-Br-C16-DX was successfully encapsulated in the oil-filled NPs with good retention in mouse plasma. The ester bond is more susceptible to hydrolysis with an electron-withdrawing group at the 2-position. 2-BrC16-DX was slowly hydrolyzed to DX to an extent of $45 \%$ in $48 \mathrm{hr}$. The sustained hydrolysis is expected to benefit the slow release of DX in-vivo and further improve the DX blood exposure.

The cytotoxicity of 2-Br-C16-DX NP was 6.5-fold and 12.7-fold higher compared to free 2Br-C16-DX in DU-145 and 4T1 cells, respectively. The higher cytotoxicity of 2-Br-C16-DX NP may be explained by increased cellular uptake and/or different cellular compartmental sequester facilitated by NP. These factors may also contribute to the higher cytotoxicity of 2-Br-C16-DX NP in the highly aggressive breast cancer cell 4T1 compared to unmodified free DX. The low sensitivity of 4T1 cells to DX is probably due to their extremely rapid proliferation as well as other intrinsic detoxification mechanisms (e.g., degradation of DX). 
Hence, the uptake of high drug payload NPs by endocytosis followed by sustained release of DX may play essential roles in the improved cytotoxicity of 2-Br-C16-DX NP in 4T1 cells.

In-vivo, NP-formulated 2-Br-C16-DX achieved 100-fold higher AUC compared to Taxotere. The remarkably high AUC, long terminal half-life and long MRT were attributed to the stable anchoring of 2-Br-C16-DX in the long-circulating NPs as predicted by the invitro release study. The elimination routes of 2-Br-C16-DX include: 1) uptake of drug containing NPs by RES, 2) release of conjugate followed by elimination as free drug, and 3) hydrolysis of the conjugate to DX. Due to sustained hydrolysis, the AUC of DX in the plasma after the administration of 2-Br-C16-DX NPs was over 4-fold higher than that of Taxotere when the DX dose was the same. The 2-Br-C16-DX NPs served as a drug reservoir and released free DX in a sustained manner. The high concentration and prolonged exposure of both 2-Br-C16-DX and DX from 2-Br-C16-DX NPs in the plasma were beneficial to their passive tumor accumulation via the EPR effect. The $\mathrm{AUC}_{\text {tumor }}$ of 2-Br-C16-DX was 10-fold higher than that of Taxotere. The $\mathrm{AUC}_{\text {tumor }}$ of DX from 2-Br-C16-DX NP was 1.5-fold greater than that of Taxotere. However, the overall ratio of $\mathrm{AUC}_{\text {tumor }}$ of DX from 2-Br-C16DX NP to that of total 2-Br-C16-DX was only $14.7 \%$ at $96 \mathrm{hr}$. The DX in the tumor was from two potential routes: direct uptake of DX from the systemic circulation and cleavage from the 2-Br-C16-DX accumulated in the tumors. The clear ascending trend of DX with time in the tumor suggests that the in-situ hydrolysis dominated the DX tumor concentration. The low ratio of hydrolysis in the tumor in-vivo suggests low esterase activity in 4T1 tumor. The non-specific esterase activity in various human malignant tumors has been studied by histochemical analysis. It has been previously reported that the esterase activity in breast tumors is generally low. ${ }^{[11,12]}$ In contrast, esterase activity is highly elevated in some tumor types compared to their normal tissue of origin such as colon and rectum adenocarcinoma, and thyroid tumors. It is likely that these tumor types with high esterase activity would serve as better models for the ester prodrugs that mostly count on the enzymatic conversion to their active forms to exert antitumor effects. The NP-formulated 2Br-C16-DX showed a marked accumulation in liver and spleen and the accumulation was increasing during the first several hours of the study, which clearly indicates a slow uptake of drug containing NPs by RES. Although PEGylation reduces RES clearance, significant accumulation in RES-related organs is unfortunately still a typical distribution pattern for most of the NPs. ${ }^{[13-16]}$

Murine breast cancer 4T1 is a highly aggressive and metastatic tumor model. 4T1 tumors spontaneously metastasize to the lung, liver, lymph nodes and brain while the primary tumor grows in-situ after injected s.c. into BALB/c mice. The tumor growth and metastatic spread of $4 \mathrm{~T} 1$ cells in BALB/c mice very closely mimic human breast cancer. ${ }^{[17,18]}$ The in-vivo efficacy study in mice bearing breast cancer 4T1 solid tumor using low dose (10 mg DX or conjugate $/ \mathrm{kg}$ ) demonstrated a statistically significant tumor growth inhibition effect by $2-\mathrm{Br}-$ C16-DX NP compared to the standard-of-care therapy, which was consistent with their superior plasma pharmacokinetics and tumor distribution. However, given the high aggressiveness of 4T1 tumor model, it is not surprising that the low dose regimen did not achieve optimal antitumor efficacy. Since 2-Br-C16-DX NP was much better tolerated than Taxotere as indicated by its higher MTD, higher doses can be given expecting to achieve maximum tumor inhibition. Total NP dose was $455 \mathrm{mg} / \mathrm{kg}$ when the conjugate was dosed at $70 \mathrm{mg} / \mathrm{kg}$. In the second efficacy study, the tumor growth was significantly suppressed by only two doses of 2-Br-C16-DX NP and the suppression effect continued to at least day 23. The long-lasting antitumor effect of 2-Br-C16-DX NP reflected its prolonged exposure in the circulation as well as in tumors. In contrast, in Taxotere treatment group, after the last treatment at day 7 , tumor growth quickly resumed. The rapid tumor growth after the termination of the treatment caused $100 \%$ mortality in 21 days despite its antitumor efficacy during the treatment. The short antitumor effect of Taxotere was consistent with its short 
half-life in-vivo. Moreover, since human plasma esterase activity is much lower than mouse, ${ }^{[19,20]}$ it can be anticipated that in human or in esterase-deficient mice, 2-Br-C16-DX $\mathrm{NP}$ will be even better tolerated than in BALB/c mice and higher doses are allowed.

\section{Conclusions}

The 2-Br-C16-DX NP developed in these studies maintained the high drug entrapment and long drug retention in the NPs while improving the hydrolysis kinetics of the conjugate invitro. The 2-Br-C16-DX NP developed in these studies had long circulation in the blood, high accumulation in the tumor and low toxicity, which therefore led to superior antitumor efficacy and less systemic toxicity in-vivo. Collectively, these studies demonstrate that the oil-filled lipid NPs containing a DX-lipid conjugate with fine-tuned lipophilicity and activation kinetics successfully improved the therapeutic index of DX. The encouraging results of these studies suggest that the novel formulation holds promise for further preclinical development.

\section{Experimental Section}

Materials and Animals: DX, PX, 2-bromohexadecanoic acid (>99\%), 4-(dimethylamino) pyridine (DMAP) and N,N'-dicyclohexyl-carboiimide (DCC, 99\%) were purchased from Sigma-Aldrich (St. Louis, MO). Miglyol 808 was obtained from Sasol (Witten, Germany). Polyoxyl 20-stearyl ether (Brij 78) was obtained from Uniqema (Wilmington, DE). D-alphatocopheryl polyethylene glycol-1000 succinate (Vitamin E TPGS) was purchased from Eastman Chemicals (Kingsport, TN). BALB/c mouse plasma was purchased from Innovative Research Inc. (Novi, MI). Sepharose CL-4B was purchased from GE Healthcare (Uppsala, Sweden). Hybrid-SPE ${ }^{\circledR}$ cartridge was purchased from Sigma-Aldrich Supelco (St. Louis, MO).

The human prostate cancer cell line DU-145, and murine breast cancer cell line 4T1 were obtained from American Type Culture Collection (ATCC) and were maintained in RPMI-1640 medium with 10\% fetal bovine serum (FBS). Female BALB/c mice, 4 to 5 weeks old, were purchased from Charles River (Wilmington, MA) and housed in a pathogen-free room. All experiments involving mice were conducted according to an approved animal protocol by the University of North Carolina Institutional Animal Care and Use Committee.

\section{General procedure for the synthesis of 2'-(2-bromohexadecanoyl)-docetaxel (2-Br-C16- DX) $)^{[7]}$}

A flame-dried round-bottom flask was charged with $( \pm)$-2-bromohexadecanoic acid $(0.62 \mathrm{~g}$, $\left.1.85 \times 10^{-3} \mathrm{~mol}, 1.5 \mathrm{~N}\right)$ and $\operatorname{DCC}\left(0.5 \mathrm{~g}, 2.47 \times 10^{-3} \mathrm{~mol}, 2 \mathrm{~N}\right)$ in dry $\mathrm{CH}_{2} \mathrm{Cl}_{2}(200 \mathrm{~mL})$ under argon. The solution was stirred for $10 \mathrm{~min}$ at room temperature. DX $(1.0 \mathrm{~g}, 1.24 \times$ $\left.10^{-3} \mathrm{~mol}, 1 \mathrm{~N}\right)$ was added along with a catalytic amount of DMAP $\left(0.15 \mathrm{~g}, 1.24 \times 10^{-3} \mathrm{~mol}\right.$, $1 \mathrm{~N})$ and the reaction mixture was stirred at room temperature for an extra $5 \mathrm{~min}$. The reaction was monitored by TLC $\left(\mathrm{CH}_{2} \mathrm{Cl}_{2}: \mathrm{MeOH} 95: 5 \mathrm{v} / \mathrm{v} ; \mathrm{Rf}=0.58\right)$ for completion. The white precipitate of dicyclohexyl urea byproduct was filtered through a fritted funnel, and the filtrate was evaporated under vaccuo. The crude product was purified by preparative TLC in $\mathrm{CHCl}_{3}: \mathrm{MeOH}$ (95:5). The silica gel was removed by filtration through a fine fritted funnel and the filtrate was evaporated under vaccuo to give the desired product as a white powder $(0.4 \mathrm{mg}, 86 \%) .{ }^{1} \mathrm{H}$ NMR $\left(400 \mathrm{MHz}, \mathrm{CDCl}_{3}\right): \delta(\mathrm{ppm})=0.8\left(\mathrm{t}, 3 \mathrm{H},-\mathrm{CH}_{3}\left(\mathrm{CH}_{2}\right)_{14}\right)$, 1.05 (s, 6H, $\left.-H_{16,17}\right), 1.16\left(\mathrm{~s}, 9 \mathrm{H},-H_{7},-9\right.$ ), 1.19 (s, 3H, $\left.-H_{19}\right), 1.23$ (m, 28H, $\left.\left(\mathrm{CH}_{2}\right)_{14} \mathrm{CH}_{3}\right), 1.68\left(\mathrm{~s}, 3 \mathrm{H},-\mathrm{H}_{18}\right), 1.78\left(\mathrm{~m}, 2 \mathrm{H},-\mathrm{H}_{14}\right), 1.67\left(\mathrm{~d}, 2 \mathrm{H},-\mathrm{CH}_{2} \mathrm{C}_{1}\right.$ "), 1.87 (s, 3H, $\left.H_{22}\right), 2.24\left(\mathrm{~m}, 1 \mathrm{H},-H_{3}\right), 2.38\left(\mathrm{~s}, 1 \mathrm{H},-H_{7}\right), 3.86\left(\mathrm{~d}, 1 \mathrm{H},-H_{4}\right), 4.12\left(\mathrm{~d}, 1 \mathrm{H},-H_{2}\right), 4.2(\mathrm{t}, 1 \mathrm{H}$, $-\mathrm{CHBrC}_{1}$ ) $), 4.26\left(\mathrm{t}, 2 \mathrm{H},-H_{13}\right), 4.88\left(\mathrm{~d}, 1 \mathrm{H},-H_{10}\right), 5.2\left(\mathrm{~d}, 2 \mathrm{H},-H_{20}\right), 5.22\left(\mathrm{~d}, 1 \mathrm{H},-H_{2}\right.$ ), 
$5.62\left(\mathrm{~d}, 1 \mathrm{H},-H_{3}\right), 7.22-7.53\left(\mathrm{~m}, 8 \mathrm{H},-\mathrm{Ar}-\mathrm{H}_{26-28}\right.$ and $\left.\mathrm{Ar}-\mathrm{H}_{30-35}\right), 8.05(\mathrm{~d}, 2 \mathrm{H},-\mathrm{Ar}-$

$\left.H_{25,29}\right) .{ }^{13} \mathrm{C}$ NMR $\left(100 \mathrm{MHz}, \mathrm{CD}_{3} \mathrm{OD}\right): \delta(\mathrm{ppm})=8.9\left(-\mathrm{C}_{19}\right), 14.1\left(-\mathrm{CH}_{3}\left(\mathrm{CH}_{2}\right)_{20}\right), 20.9(-$

$\left.\mathrm{C}_{18}\right), 22.6\left(-C_{22}\right), 23.7\left(-\left(\mathrm{CH}_{2}\right)_{19} \mathrm{CH}_{2} \mathrm{CH}_{3}\right), 27\left(-C_{16,17}\right), 28.1\left(-C_{7},-9^{\prime}\right), 29.6$ (-

$\left.\left(\mathrm{CH}_{2}\right)_{14} \mathrm{C}_{1}{ }^{\prime}\right), 31.9\left(-C_{6,14}\right), 43.1\left(-C_{15}\right), 44.5\left(-C_{3}\right), 45(-C \mathrm{HBr}), 46.4\left(-C_{3}\right), 57.5\left(-C_{8}\right)$,

$71.8\left(-C_{13}\right), 72.1\left(-C_{7}\right), 74.4\left(-C_{2}\right), 75\left(-C_{10}\right), 75.3\left(-C_{20}\right), 78.9\left(-C_{6}\right), 79.9\left(-C_{1}\right), 80.9(-$

$\left.C_{4}\right), 84.2\left(-C_{5}\right), 126.3\left(-C_{31,33,35}\right), 128.9\left(-C_{32,34}\right), 129.2\left(-C_{26,28}\right), 130.2\left(-C_{24,25,29}\right)$,

$133.6\left(-C_{27}\right), 135.5\left(-C_{11}\right), 138.9\left(-C_{12}\right), 154.2\left(-C_{5}\right), 167\left(-C_{23}\right), 167.3\left(-C_{21}\right), 169\left(-C_{1}\right)$, $169.7\left(-C_{1}\right), 211.5\left(-C_{9}\right)$.

\section{Characterization of DX and DX conjugates}

Electrospray Ionization (ESI) coupled with direct injection was employed to determine the $\mathrm{m} / \mathrm{z}$ of the final synthetic conjugate product by Thermo Scientific TSQ Quantum Access with positive ionization. The $\mathrm{m} / \mathrm{z}$ of the observed molecular ion was 1125 , which clearly corresponded to the $\mathrm{H}^{+}$adduct of 2-Br-C16-DX.

The 2-Br-C16-DX concentrations were quantified by HPLC using a Finnigan Surveyor HPLC system with a Photodiode Array (PDA) detector, autosampler and LC pump plus with a Inertsil ${ }^{\circledR}$ ODS-3 column ( $4 \mu \mathrm{m}, 4.6 \times 150 \mathrm{~mm}$, GL Sciences) at $25^{\circ} \mathrm{C}$. Chromatographic separation was achieved by gradient elution using mobile phase 2-propanol, acetonitrile $(\mathrm{ACN})$ and water $(5: 55: 40 \mathrm{v} / \mathrm{v} / \mathrm{v})$. The flow rate was $1.0 \mathrm{~mL} / \mathrm{min}$ and the total run time was $25 \mathrm{~min}$ for each $25 \mu \mathrm{L}$ injection. The wavelength was $230 \mathrm{~nm}$. The DX concentration was quantified by LC/MS/MS as described previously. ${ }^{[4]}$

\section{2-Br-C16-DX digestion in fresh mouse plasma}

The esterase digestion study was performed in fresh BALB/c mouse plasma. The 2-Br-C16DX NPs $(0.5 \mathrm{mg} / \mathrm{mL})$ were spiked into the plasma to make a final concentration of $10 \mu \mathrm{g} /$ $\mathrm{mL}$. The mixture was incubated at $37^{\circ} \mathrm{C}$ in a water bath shaker. At designated time points, $100 \mu \mathrm{L}$ of digestion mixture was removed. The concentration of 2-Br-C16-DX was determined by Hybrid-SPE precipitate method as described previously followed by HPLC analysis. ${ }^{[4]}$ The $\%$ 2-Br-C16-DX remaining at any time point was calculated as $100 \% \times$ the ratio of remaining drug amount to the total drug spiked into this volume of plasma. The concentration of DX in the same sample was determined by LC/MS/MS. The \% 2-Br-C16DX hydrolyzed to DX at any time point was calculated as $100 \% \times[(\mathrm{DX}$ amount detected $\times$ 1124 / 807)/ the total drug spiked into this volume of plasma].

\section{Preparation and characterization of 2-Br-C16-DX NPs}

NPs containing 2-Br-C16-DX were prepared using a warm oil-in-water $(\mathrm{o} / \mathrm{w})$ microemulsion precursor method previously developed and later optimized in our laboratory. ${ }^{[4,21]}$ For in-vivo studies, NPs were concentrated and PEGylated. The formulation was concentrated 4-13-fold by adding 4-13-fold less $10 \%$ lactose continuous phase while keeping the other components of the formulation unchanged. The NPs were PEGylated by adding $8 \%$ Brij 700 during the preparation wherein $8 \%$ was the w/w ratio of Brij 700 to Miglyol 808.

Particle size and the zeta potential of NPs were determined as previously described. ${ }^{[4]}$ Drug entrapment efficiency was determined by size exclusion chromatography (SEC) as previously described. ${ }^{[4]}$ The 2-Br-C16-DX NP suspension was stored at $4{ }^{\circ} \mathrm{C}$. At designated time points, the particle size was measured after the NP suspension being allowed to equilibrate to room temperature. The 2-Br-C16-DX concentration was then determined by HPLC. 


\section{In-vitro drug release in mouse plasma}

In-vitro release studies were performed in $100 \%$ plasma from BALB/c mice. Briefly, $100 \mu \mathrm{L}$ of purified DX conjugate NPs were spiked into $2 \mathrm{~mL}$ of mouse plasma. The release mixture was incubated at $37^{\circ} \mathrm{C}$ in a water bath shaker. At designated time points from $0 \mathrm{hr}$ to $8 \mathrm{hr}$, two aliquots of release mixture were removed. One aliquot $(100 \mu \mathrm{L})$ was used to determine the total drug concentration by solid phase extraction (SPE) using Hybrid-SPE precipitate method. Briefly, one volume of release mixture was mixed with three volumes of $2 \%$ formic acid in ACN. Following vortex and centrifugation, the supernatant was applied to a HybridSPE cartridge. The eluate was collected for HPLC analysis. Another aliquot $(100 \mu \mathrm{L})$ was used to determine the drug remained in the NPs using the method described in drug entrapment efficiency determination. The Sepharose CL-4B column was able to achieve baseline separation of the NPs with plasma proteins and free drugs, validated by dynamic light scattering intensity, BCA assay and HPLC analysis (data not shown). The \% DX released at any time point was calculated as $100 \% \times$ [(Total drug detected - drug remaining in the NPs)/Total drug detected].

\section{Evaluation of in-vitro cytotoxicity}

The MTT assay was utilized to assess cytotoxicity of free 2-Br-C16-DX and the 2-Br-C16DX NPs. Serial dilutions of free drugs or drug containing NPs were added to the DU-145 cells or $4 \mathrm{~T} 1$ cells and incubated for $48 \mathrm{hr}$. The cells were then incubated with MTT solution for $4 \mathrm{hr}$ and the formazan dyes were solubilized by DMSO. The absorbance was measured at a wavelength of $570 \mathrm{~nm}$, and the concentration of drug that inhibited cell survival by $50 \%$ $\left(\mathrm{IC}_{50}\right)$ was determined from cell survival plots.

\section{In-vivo pharmacokinetics of 2-Br-C16-DX NPs}

Female BALB/c mice were injected s.c. in the right flank $1 \times 10^{-6} 4 \mathrm{~T} 1$ cells suspended in $100 \mu \mathrm{L}$ of FBS-free RPMI-1640 medium. When the tumor volume reached $400-500 \mathrm{~mm}^{3}$, mice were randomly divided into two groups. The mice $(n=3 /$ time point) were injected via tail vein with Taxotere or 2-Br-C16-DX NPs, all at a DX dose of $10 \mathrm{mg} / \mathrm{kg}$. At designated time points from $3 \mathrm{~min}$ to $96 \mathrm{hr}$, the mice were given an overdose of ketamine $(100 \mathrm{mg} / \mathrm{kg})$ and domitor $(0.5 \mathrm{mg} / \mathrm{kg})$ for deep anesthesia prior to cardiac puncture to collect blood and a cervical dislocation was then performed to euthanize the mice. After euthanasia, organs (heart, liver, spleen, lung and kidney) and tumor were collected and flash frozen in liquid nitrogen. For plasma separation, the blood collected in heparin-coated tubes was centrifuged at 12,300 rpm for $15 \mathrm{~min}$. The obtained plasma was processed with Hybrid-SPE precipitate method as described above. For organs and tumor, $300 \mu \mathrm{L}$ of $2 \%$ formic acid in ACN was added to every $100 \mathrm{mg}$ of tissues. Tissues were homogenized using Omni Bead Ruptor 24 homogenizer with $2.8 \mathrm{~mm}$ zirconium oxide beads. Following vortex and centrifugation, the supernatant was applied to a Hybrid-SPE cartridge. The eluate was collected for analysis. The concentrations of 2-Br-C16-DX in plasma and tissue extract were determined by HPLC, and the DX concentrations were quantified by LC/MS. Pharmacokinetic analysis and modeling was performed by WinNonlin (version 5.2.1; Pharsight Corp, Mountain View, CA).

\section{In-vivo antitumor efficacy}

Female BALB/c mice were injected s.c. in the right flank $1 \times 10^{-6} 4 \mathrm{~T} 1$ cells suspended in $100 \mu \mathrm{L}$ of FBS-free RPMI-1640 medium. When the tumor volume reached $70-100 \mathrm{~mm}^{3}$, mice were randomly divided into multiple groups. In the first efficacy study, the mice $(\mathrm{n}=$ 8) were injected via tail vein with test samples twice per week (10 mg conjugate/kg from 2Br-C16-DX NPs, $10 \mathrm{mg}$ DX/kg from Taxotere, and $10 \mathrm{mg}$ conjugate/kg from 2-Br-C16-DX in the Taxotere vehicle). In the second efficacy study, the mice $(n=9)$ were injected via tail 
vein with test samples Q7d $\times 2$ (70 mg conjugate $/ \mathrm{kg}$ from 2-Br-C16-DX NPs, $70 \mathrm{mg} / \mathrm{kg}$ equivalent blank NPs, $20 \mathrm{mg}$ DX/kg from Taxotere, and $10 \mathrm{mg}$ conjugate $/ \mathrm{kg}$ from 2-BrC16-DX in the Taxotere vehicle). Tumor volume was measured by caliper three times per week. Tumor volume was calculated as length $\times(\text { width })^{2} / 2$. The body weight and body conditions were monitored as well. Tumor growth and mouse mortality were recorded until day 23. Percentage survival of each group was calculated and plotted for the second efficacy study.

\section{Statistical analysis}

Statistical comparisons were performed using analysis of variances (ANOVA) $\left({ }^{\odot} 1992-2007\right.$ GraphPad Prism Software, Inc.). Results were considered significant at $95 \%$ confidence interval $(\mathrm{P}<0.05)$.

\section{Acknowledgments}

This research was supported by NIH-NCI R01 CA115197 and NIH-NCI U54 CA151652. The content is solely the responsibility of the authors and does not necessarily represent the official views of the National Cancer Institute or the National Institutes of Health. The authors thank Mianmian Sun for providing technical support of HPLC and mass spectrometry. The authors are very grateful to Charlene M. Santos and the Animal Studies Core at UNC Lineberger Comprehensive Cancer Center for their assistance with all animal studies.

\section{References}

1. Goldspiel BR. Pharmacotherapy. 1997; 17:110S. [PubMed: 9322878]

2. van Oosterom AT, Schrijvers D, Schriivers D. Anti-cancer drugs. 1995; 6:356. [PubMed: 7670133]

3. Cortes JE, Pazdur R. J Clin Oncol. 1995; 13:2643. [PubMed: 7595719]

4. Feng L, Wu H, Ma P, Mumper RJ, Benhabbour SR. Int J Nanomedicine. 2011; 6:2545. [PubMed: 22072889]

5. Huynh L, Leroux JC, Allen C. Org Biomol Chem. 2009; 7:3437. [PubMed: 19675898]

6. Parness J, Kingston DG, Powell RG, Harracksingh C, Horwitz SB. Biochem Biophys Res Commun. 1982; 105:1082. [PubMed: 6124250]

7. Ali S, Ahmad I, Peters A, Masters G, Minchey S, Janoff A, Mayhew E. Anticancer Drugs. 2001; 12:117. [PubMed: 11261884]

8. Ahmad I, Masters GR, Schupsky JJ, Nguyen J, Ali S, Janoff AS, Mayhew E. Oncol Res. 1999; 11:273. [PubMed: 10691029]

9. van Tellingen O, Beijnen JH, Verweij J, Scherrenburg EJ, Nooijen WJ, Sparreboom A. Clin Cancer Res. 1999; 5:2918. [PubMed: 10537361]

10. Zhigaltsev IV, Winters G, Srinivasulu M, Crawford J, Wong M, Amankwa L, Waterhouse D, Masin D, Webb M, Harasym N, Heller L, Bally MB, Ciufolini MA, Cullis PR, Maurer N. Journal of Controlled Release. 2010; 144:332. [PubMed: 20202473]

11. Cohen RB, Nachlas MM, Seligman AM. Cancer Res. 1951; 11:709. [PubMed: 14870134]

12. Kim JK, Yuan H, Nie J, Yang YT, Leggas M, Potter PM, Rinehart J, Jay M, Lu X. Small. 2012; 8:2895. [PubMed: 22777758]

13. Yang SC, Lu LF, Cai Y, Zhu JB, Liang BW, Yang CZ. Journal of Controlled Release. 1999; 59:299. [PubMed: 10332062]

14. Harivardhan Reddy L, Sharma RK, Chuttani K, Mishra AK, Murthy RS. Journal of Controlled Release. 2005; 105:185. [PubMed: 15921775]

15. Duan X, Li Y. Small. 2012

16. Faure AC, Dufort S, Josserand V, Perriat P, Coll JL, Roux S, Tillement O. Small. 2009; 5:2565. [PubMed: 19768700]

17. Aslakson CJ, Miller FR. Cancer Res. 1992; 52:1399. [PubMed: 1540948]

18. Pulaski BA, Terman DS, Khan S, Muller E, Ostrand-Rosenberg S. Cancer Res. 2000; 60:2710. [PubMed: 10825145] 
19. Xu Z, Chen L, Gu W, Gao Y, Lin L, Zhang Z, Xi Y, Li Y. Biomaterials. 2009; 30:226. [PubMed: 18851881]

20. Li B, Sedlacek M, Manoharan I, Boopathy R, Duysen EG, Masson P, Lockridge O. Biochem Pharmacol. 2005; 70:1673. [PubMed: 16213467]

21. Dong XW, Mattingly CA, Tseng M, Cho M, Adams VR, Mumper RJ. European Journal of Pharmaceutics and Biopharmaceutics. 2009; 72:9. [PubMed: 19111929]

\section{Biographies}

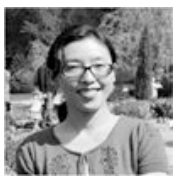

Lan Feng, Ph.D. received a B.S. degree in Biopharmaceutics in 2001 and a M.S. in Pharmaceutics in 2004 from China Pharmaceutical University, Nanjing, P.R. China. She earned her Ph.D. in Molecular Pharmaceutics from UNC Eshelman School of Pharmacy, University of North Carolina with research on lipid nanoparticles for targeted delivery of chemotherapeutics.

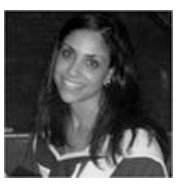

Soumya R. Benhabbour, Ph.D. is a Research Assistant Professor in the UNC Eshelman School of Pharmacy. Dr. Benhabbour received her Ph.D. degree in chemistry from McMaster University and a M.S. degree in chemistry from the University of Minnesota.

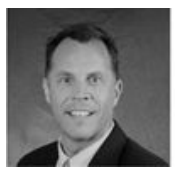

Russell J. Mumper, Ph.D. is Vice Dean and the John A. McNeill Distinguished Professor in the UNC Eshelman School of Pharmacy. Dr. Mumper has 25 years of experience in the pharmaceutical/biotechnology industries and academia with expertise in advanced drug delivery systems and product development and commercialization. 
Feng et al.

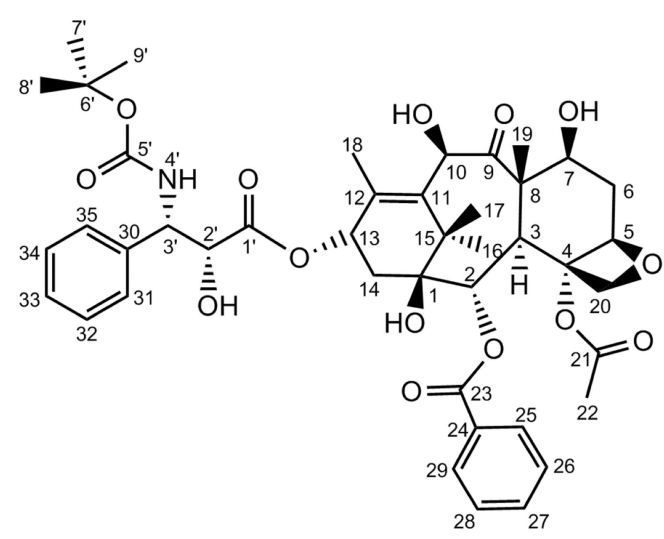

Page 11

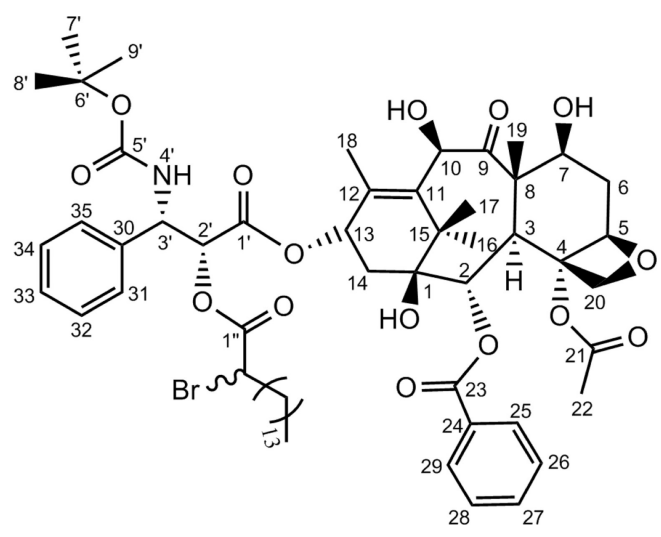

Figure 1.

Synthesis of 2'-(2-bromohexadecanoyl)-docetaxel conjugate<smiles>CC(CCC(C)(C)C)C(=O)O</smiles> 


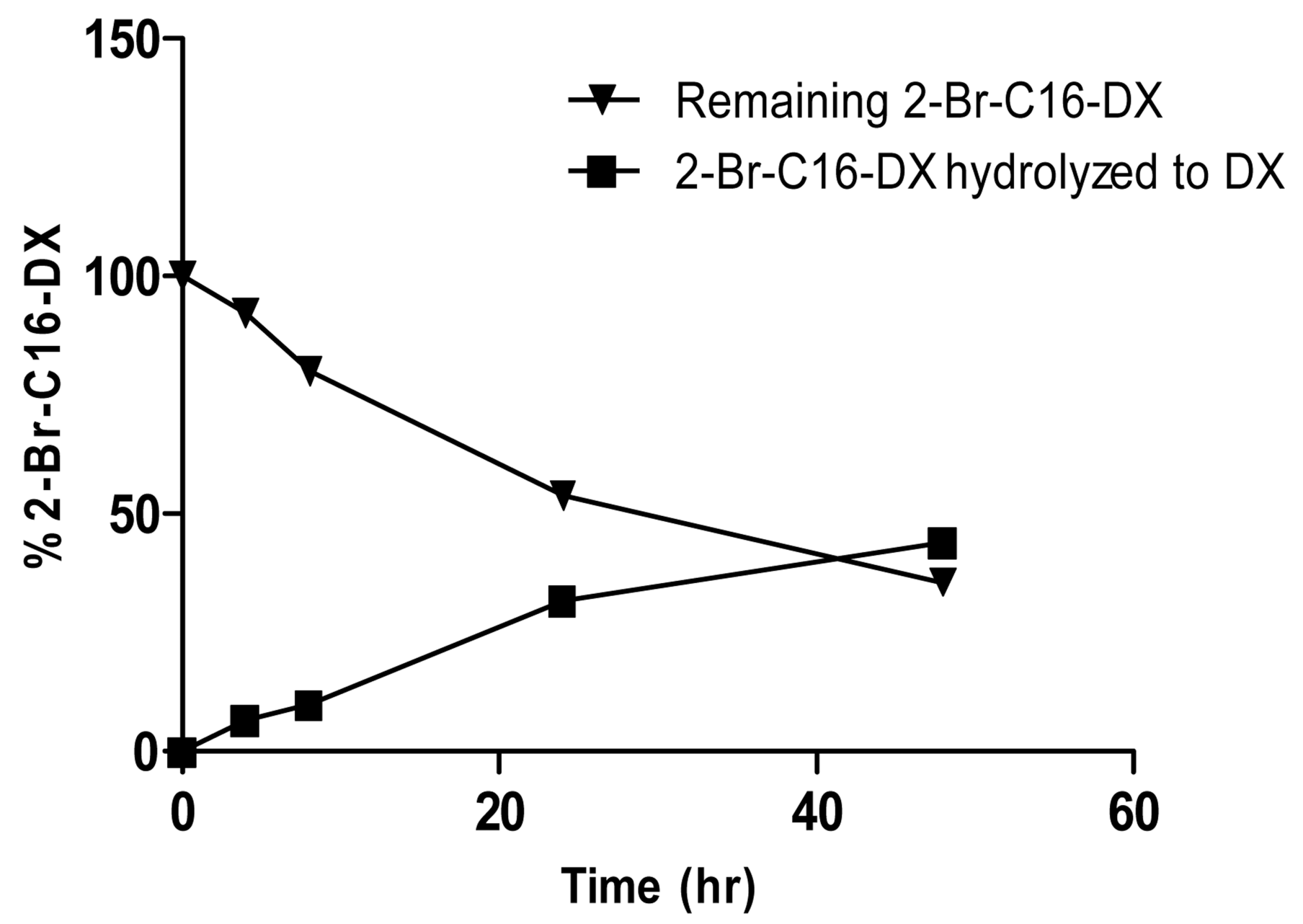

Figure 2.

The digestion of 2-Br-C16-DX in fresh $100 \%$ mouse plasma at $37^{\circ} \mathrm{C}$. Data are shown as mean $\pm \mathrm{SD}(\mathrm{n}=3)$. 


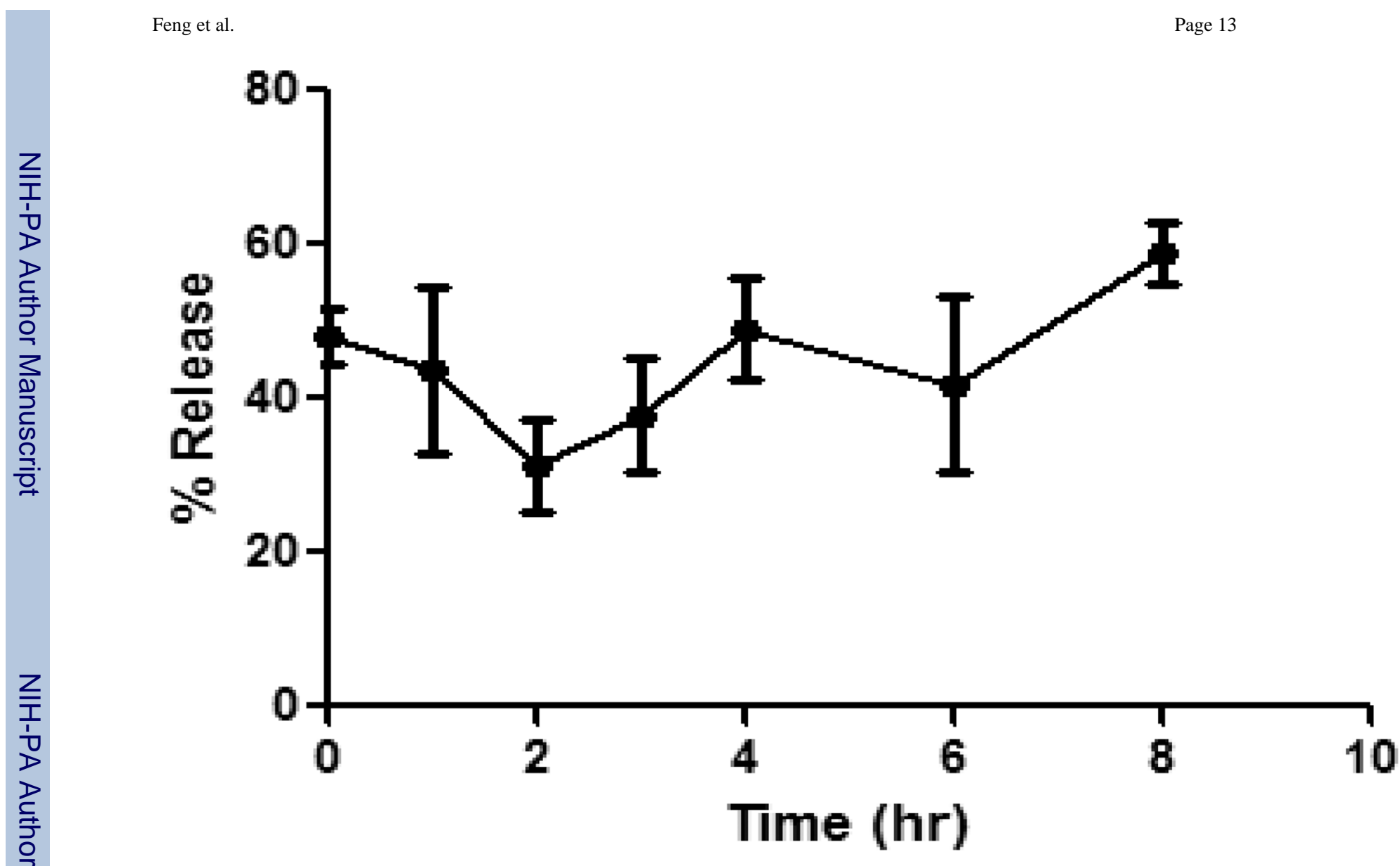

Figure 3.

Release of 2-Br-C16-DX from NPs in $100 \%$ mouse plasma at $37^{\circ} \mathrm{C}$. 
A
B

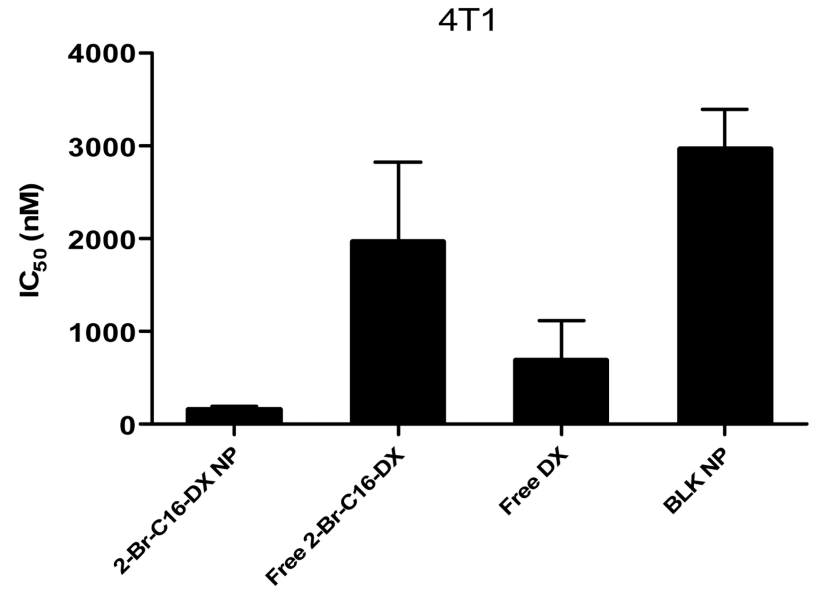

Figure 4.

In-vitro cytotoxicity of free 2-Br-C16-DX and 2-Br-C16-DX NPs in (A) human prostate cancer cell DU-145 cells and (B) murine breast cancer cell 4T1 cells. Blank NPs were dosed at drug equivalent dose. Drug equivalent dose of NPs are calculated from the NP compositions. 
A

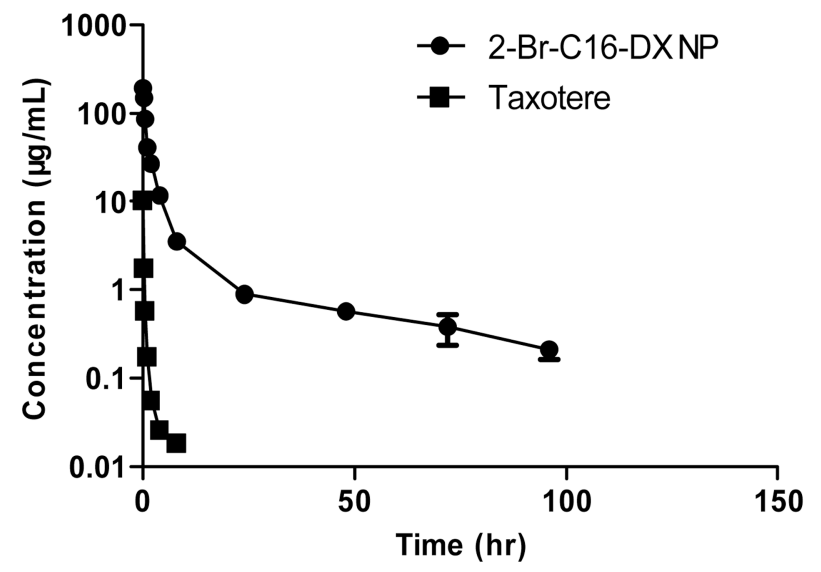

B

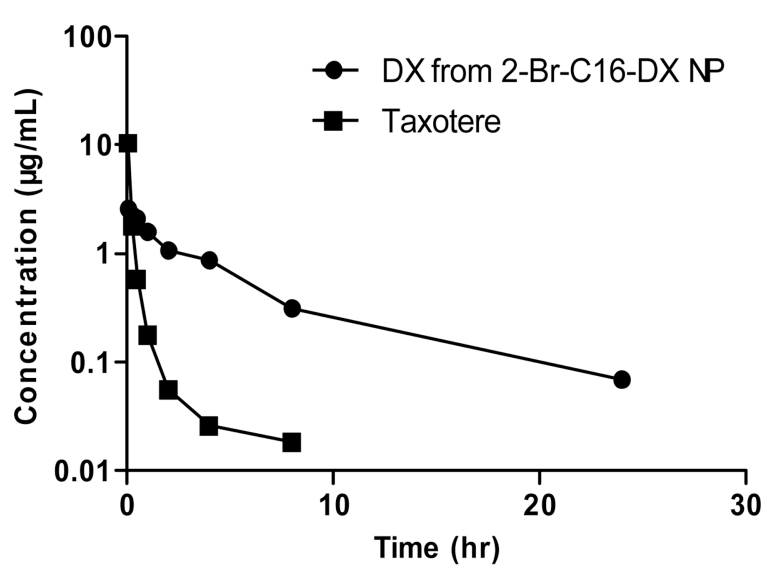

Figure 5.

Plasma concentration-time curves for (A) DX and 2-Br-C16-DX after administration of Taxotere and 2-Br-C16-DX NPs (10 mg DX/kg from each), and (B) DX as an active metabolite from 2-Br-C16-DX NPs using Taxotere as a reference. Data are shown as mean \pm $\operatorname{SD}(n=3)$. 
A

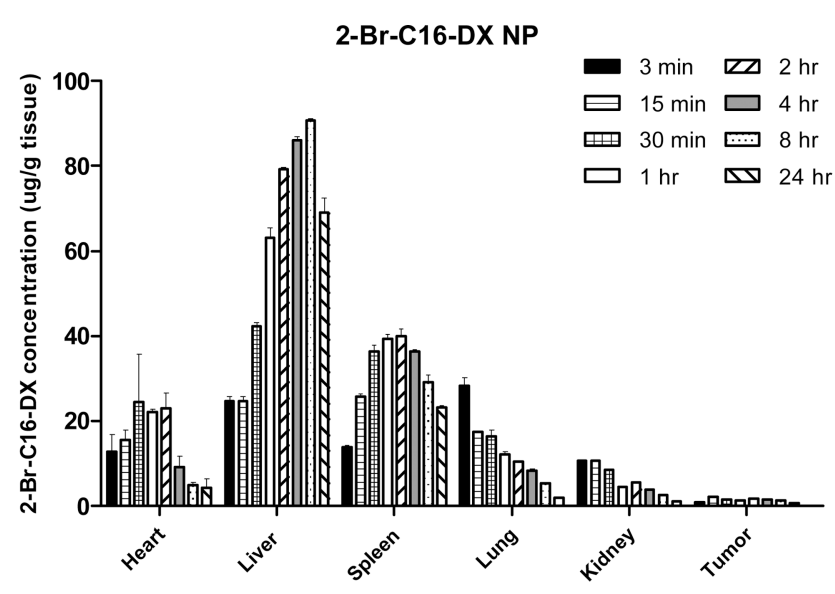

B

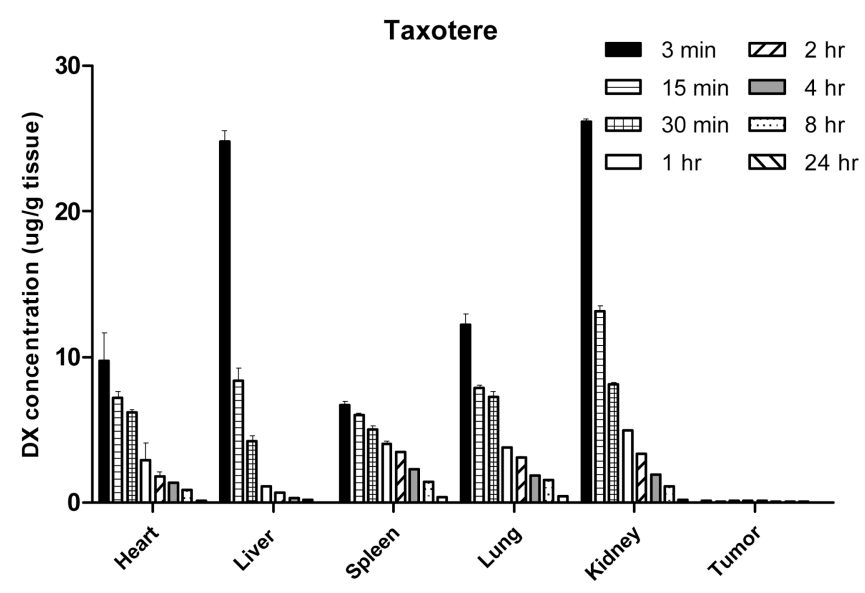

Figure 6.

Biodistribution of (A) 2-Br-C16-DX and (B) DX in heart, liver, spleen, lung, kidney and tumor after i.v. administration of 2-Br-C16-DX NP and Taxotere (10 mg DX/kg from each). Data are shown as mean $\pm \operatorname{SD}(n=3)$. 
A

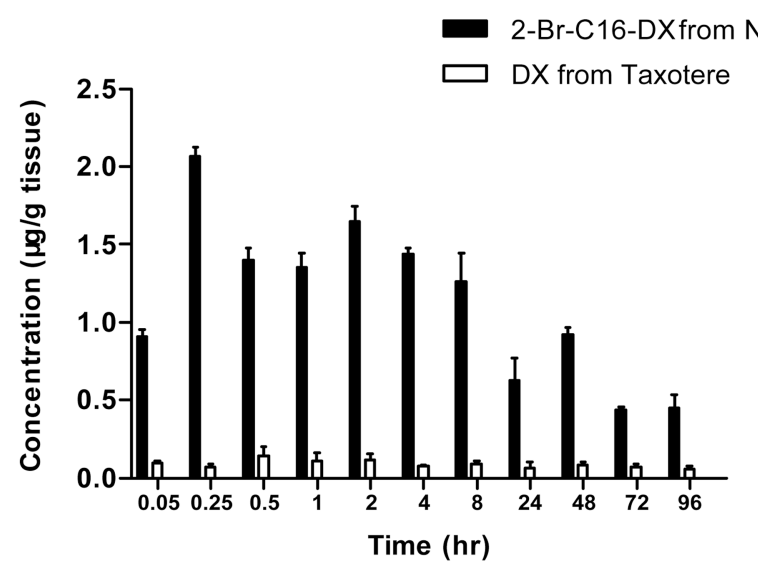

B

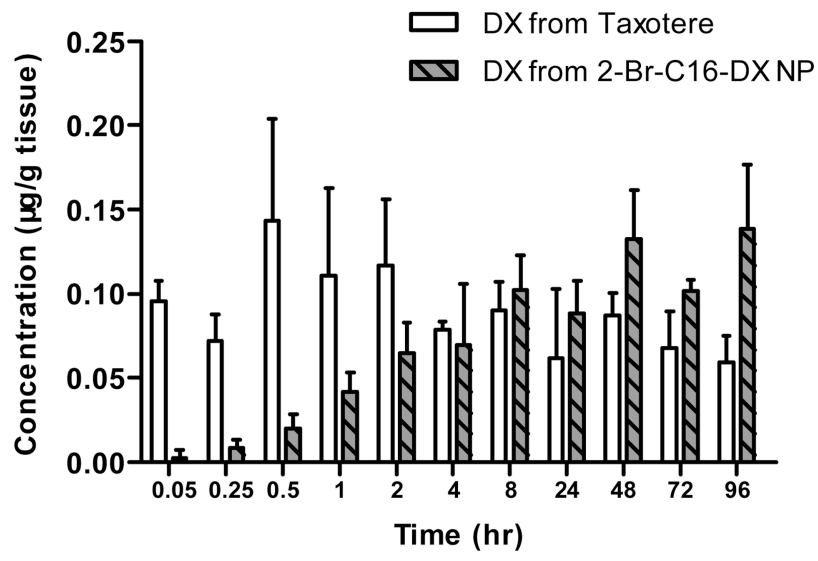

Figure 7.

Tumor accumulation of (A) 2-Br-C16-DX from NPs and DX from Taxotere, and (B) DX as an active metabolite from 2-Br-C16-DX NPs after i.v. administration of 2-Br-C16-DX NP and Taxotere $(10 \mathrm{mg} D X / \mathrm{kg})$ using Taxotere as a reference. Data are shown as mean $\pm \mathrm{SD}$ $(\mathrm{n}=3)$. 


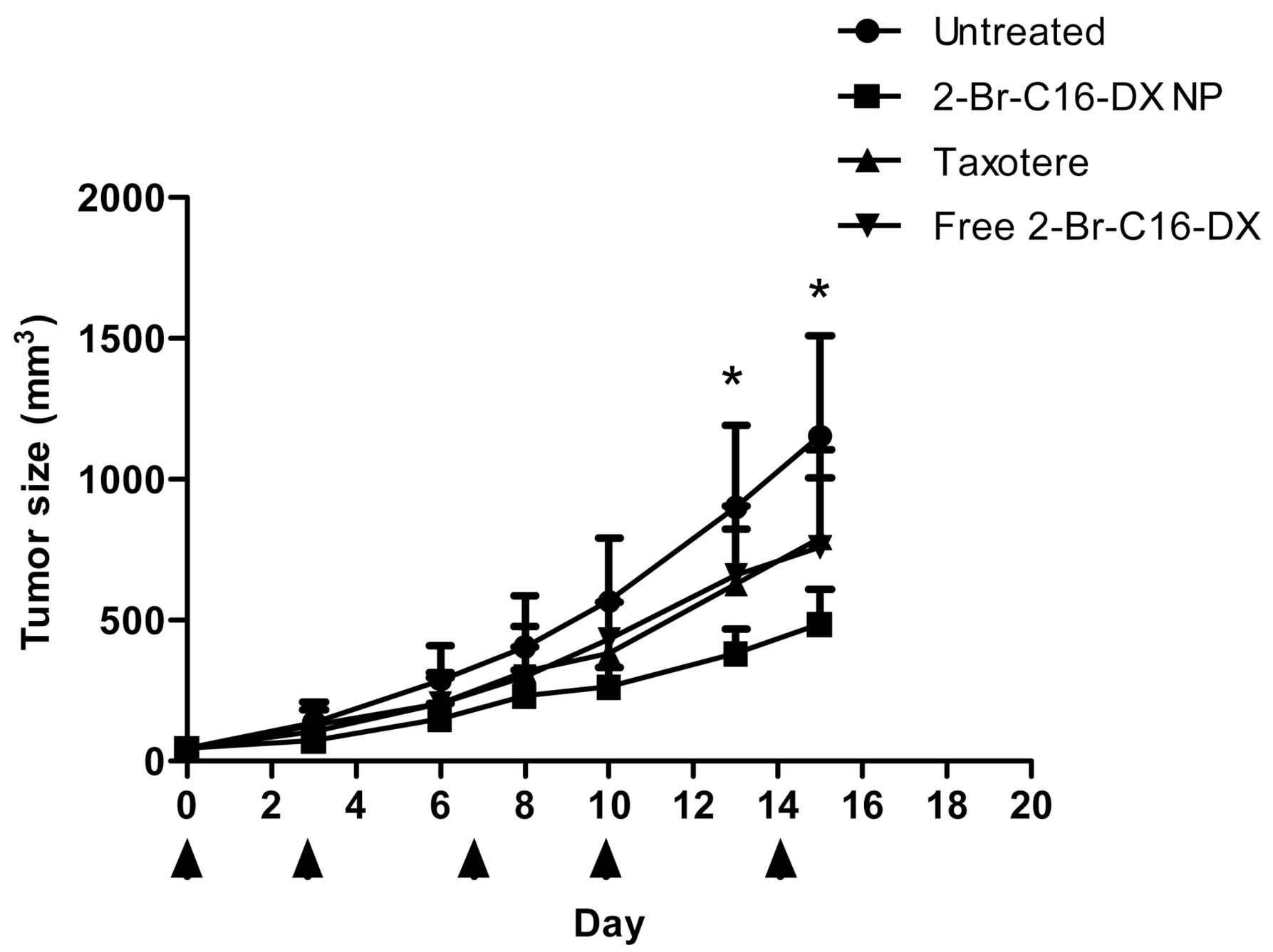

Figure 8.

The first antitumor efficacy study. 4T1 bearing female BALB/c mice bearing $70-100 \mathrm{~mm}^{3}$ tumor were treated i.v. with $10 \mathrm{mg}$ conjugate $/ \mathrm{kg}$ from 2-Br-C16-DX NPs, $10 \mathrm{mg}$ DX/kg from Taxotere, or $10 \mathrm{mg}$ conjugate $/ \mathrm{kg}$ from $2-\mathrm{Br}-\mathrm{C} 16-\mathrm{DX}$ in the Taxotere vehicle on day 0 , $3,7,10$, and 14. Data are shown as mean $\pm \operatorname{SD}(\mathrm{n}=8) . * p<0.05$. 


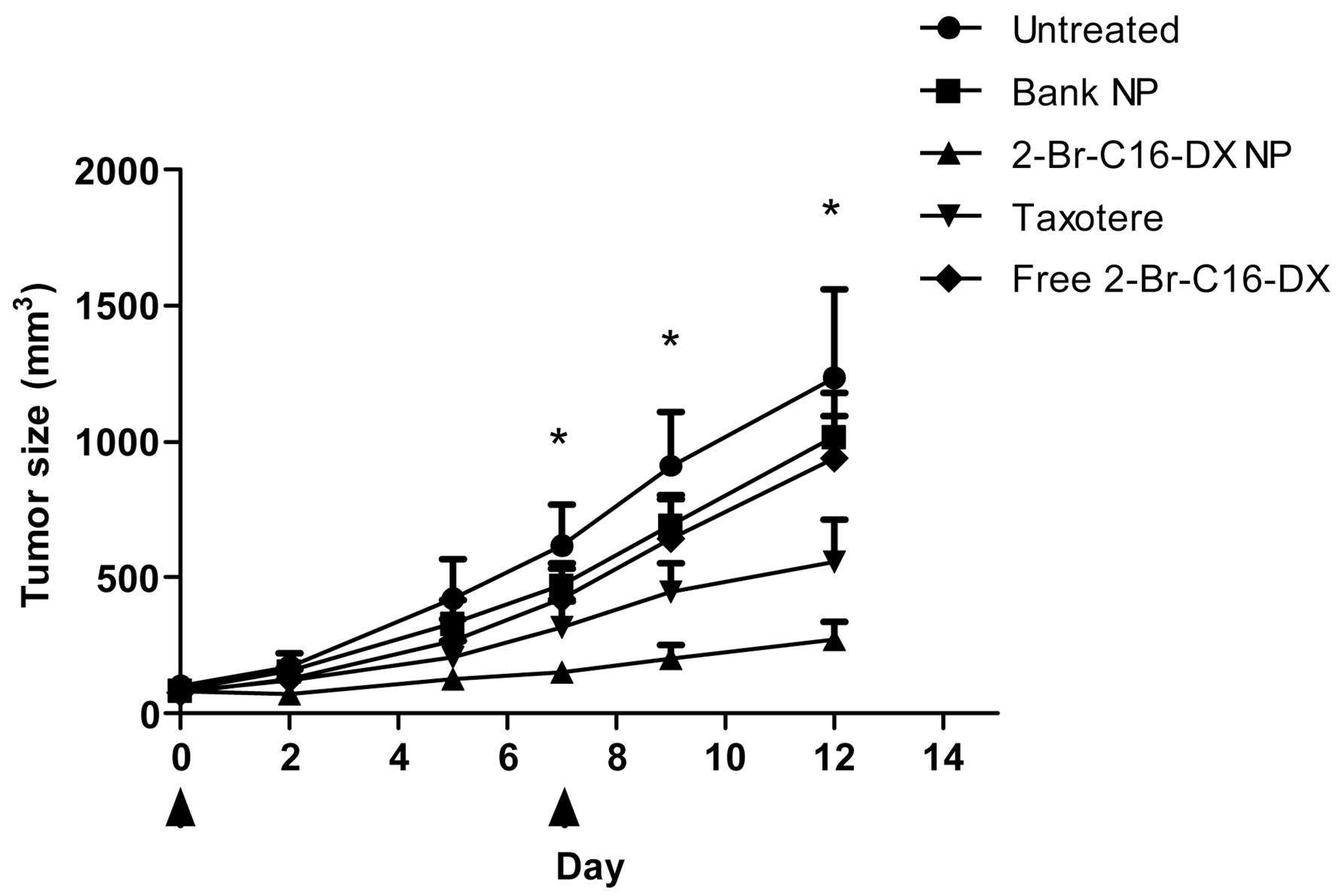

Figure 9.

The second antitumor efficacy study. 4T1 bearing female BALB/c mice bearing $70-100$ $\mathrm{mm}^{3}$ tumor were treated i.v. with $70 \mathrm{mg}$ conjugate $/ \mathrm{kg}$ from 2-Br-C16-DX NPs, $70 \mathrm{mg} / \mathrm{kg}$ equivalent blank NPs, $20 \mathrm{mg}$ DX/kg from Taxotere, or $10 \mathrm{mg}$ conjugate $/ \mathrm{kg}$ from 2-Br-C16DX in the Taxotere vehicle on day 0 and 7. Data are shown as mean $\pm \mathrm{SD}(\mathrm{n}=9)$. $* p<$ 0.05 . 


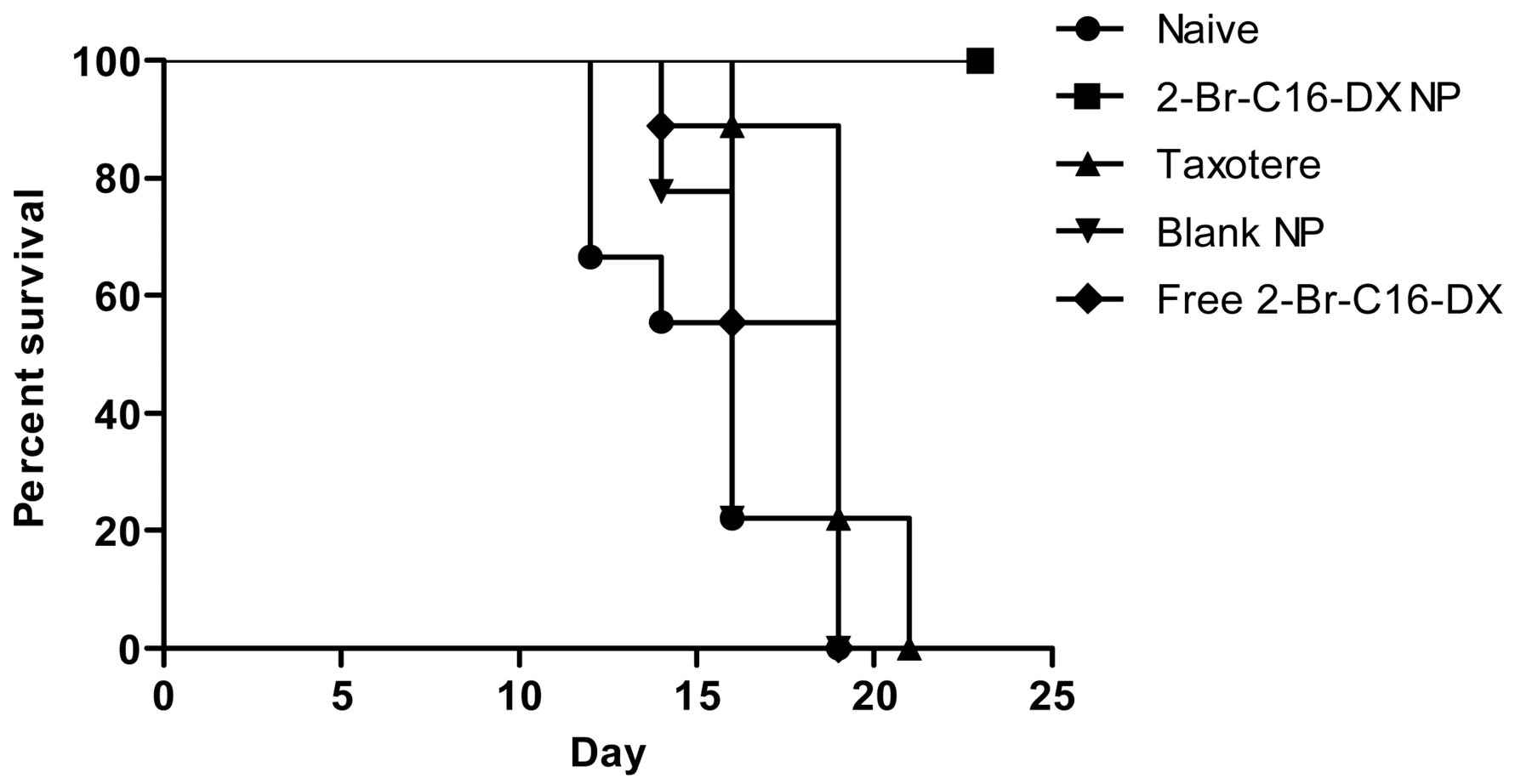

Figure 10.

Kaplan-Meier survival curves of $4 \mathrm{~T} 1$ bearing female BALB/c mice treated with $70 \mathrm{mg}$ conjugate $/ \mathrm{kg}$ from 2-Br-C16-DX NPs, $70 \mathrm{mg} / \mathrm{kg}$ equivalent blank NPs, $20 \mathrm{mg} \mathrm{DX} / \mathrm{kg}$ from Taxotere, or $10 \mathrm{mg}$ conjugate/kg from 2-Br-C16-DX in Taxotere vehicle $(\mathrm{n}=9)$ on day 0 and 7. 


\section{Table 1}

Pharmacokinetic parameters of 2-Br-C16-DX and DX in mice after i.v. bolus administration of 2-Br-C16-DX $\mathrm{NP}$ and Taxotere (10 $\mathrm{mg} \mathrm{DX/kg} \mathrm{from} \mathrm{each)}$

\begin{tabular}{cccc}
\hline & Taxotere & $\begin{array}{c}\text { NP-formulated 2-Br- } \\
\text { C16-DX }\end{array}$ & $\begin{array}{c}\text { DX from 2-Br-C16- } \\
\text { DX NP }\end{array}$ \\
\hline $\mathrm{t}_{1 / 2}(\mathrm{hr})$ & 4.04 & 35.3 & 5.62 \\
$\mathrm{AUC}_{0-96}(\mathrm{~h} * \mathrm{mg} / \mathrm{L})$ & 2.36 & 230 & 10.1 \\
$\mathrm{AUC}_{0-\infty}(\mathrm{h} * \mathrm{mg} / \mathrm{L})$ & 2.47 & 265 & 10.6 \\
$\mathrm{~V}_{\mathrm{d}}(\mathrm{L} / \mathrm{kg})$ & 4.48 & 0.55 & -- \\
$\mathrm{K}_{\mathrm{el}}(1 / \mathrm{hr})$ & 0.17 & 0.02 & 0.12 \\
$\mathrm{CL}(\mathrm{L} / \mathrm{hr} / \mathrm{kg})$ & 4.05 & 0.04 & -- \\
$\mathrm{C}_{\mathrm{max}}(\mathrm{mg} / \mathrm{L})$ & 10.5 & 192 & 2.59 \\
$\mathrm{MRT}(\mathrm{hr})$ & 1.10 & 15.2 & 7.06 \\
\hline
\end{tabular}




\section{Table 2}

Tumor accumulation of 2-Br-C16-DX and DX in mice after i.v. bolus administration of 2-Br-C16-DX NP and Taxotere

\begin{tabular}{lccc}
\hline & Taxotere & $\begin{array}{c}\text { NP-formulated 2-Br-C16- } \\
\text { DX }\end{array}$ & $\begin{array}{c}\text { DX from 2-Br-C16-DX } \\
\text { NP }\end{array}$ \\
\hline $\mathrm{AUC}_{0-96}(\mu \mathrm{g} / \mathrm{g} * \mathrm{~h})$ & 7.10 & 70.6 & 10.4 \\
\hline
\end{tabular}

